\title{
O DILEMA DISTRIBUTIVO DAS PETROFEDERAÇÕES: COMO ESCAPAR DA MALDIÇÃO DOS RECURSOS NATURAIS?
}

\author{
Enrique Natalino*
}

\begin{abstract}
Resumo: O trabalho se propõe é analisar o problema da Maldição do Petróleo sob a perspectiva dos petro-Estados e das petrofederações, abordando as diversas experiências de Estados que possuem economias voltadas, em maior ou menor grau, à exploração do petróleo, bem como os diversos arranjos institucionais e distributivos existentes. A existência de uma relação entre a instabilidade econômica e política de nações que exportam petróleo e a existência de instituições fracas é um tema estudado pela literatura da Economia Política há várias décadas. Tanto a estruturação do Estado quanto os arranjos políticos distributivos construídos sob a égide de um modelo dependente do petróleo teriam enrijeceriam as possibilidades de escolhas de escolhas desses países, ajudando a explicar as suas trajetórias. Utilizando abordagens neoinstitucionalistas (KARL, 1997; ROSS, 2015), procura-se mostrar como a administração de problemas econômicos nos petro-Estados dependeu de um conjunto de incentivos e regras que balizaram os atores politicos, afetando decisivamente os resultados alcançados. Nesse sentido, o paper buscou analisar o impacto da redistribuição das rendas do petróleo em federações como Brasil, Argentina, México, Canadá, Estados Unidos, Rússia, Índia, Nigéria e Austrália para entender se a maior descentralização ajudaria a combater ou agravaria os problemas advindos da Maldição dos Recursos Naturais. Ao invés de crescimento econômico e distribuição de renda, ao serem mal administrados e distribuídos, os recursos do petróleo levariam a padrões rentistas de comportamento, ao descontrole fiscal, à redução da diversificação econômica, agravando a desigualdade, a corrupção e podendo levar, no limite, a saídas autoritárias e a conflitos armados.
\end{abstract}

\footnotetext{
* Doutor em Ciência Política (UFMG)
} 
Palavras-chave: Petróleo; Federalismo; Maldição dos Recursos Naturais

Resumén: El trabajo se propone analizar el problema de la maldición del petróleo desde la perspectiva de los petroestados y las petrofederaciones, abordando las diversas experiencias de Estados que tienen economías enfocadas, en mayor o menor grado, en la exploración petrolera, así como los diversos arreglos existentes. institucional y distributiva La existencia de una relación entre la inestabilidad económica y política de las naciones exportadoras de petróleo y la existencia de instituciones débiles ha sido un tema estudiado en la literatura de Economía Política durante varias décadas. Tanto la estructuración del Estado como los arreglos políticos distributivos construidos bajo la égida de un modelo dependiente del petróleo habrian estrechado las posibilidades de elección de estos países, ayudando a explicar sus trayectorias. Utilizando enfoques neoinstitucionalistas (KARL, 1997; ROSS, 2015), buscamos mostrar cómo la administración de los problemas económicos en los petroestados dependía de un conjunto de incentivos y reglas que guiaron a los actores politicos, afectando de manera decisiva los resultados alcanzados. En este sentido, el trabajo buscó analizar el impacto de la redistribución de los ingresos petroleros en federaciones como Brasil, Argentina, México, Canadá, Estados Unidos, Rusia, India, Nigeria y Australia para entender si una mayor descentralización ayudaría a combatir o agravar los problemas que surgen de la maldición de los recursos naturales. En lugar de crecimiento económico y distribución del ingreso, cuando se administran y distribuyen de manera deficiente, los recursos petroleros llevarian a patrones de comportamiento rentistas, falta de control fiscal, reducción de la diversificación económica, agravar la desigualdad, la corrupción y potencialmente conducir a salidas autoritarias y conflictos armados.

Abstract: The article proposes to analyze the problem of the Oil Curse from the perspective of petro-States and petrofederations, addressing the various experiences of States that have economies focused, to a greater or lesser degree, on oil exploration, as well as the various arrangements existing institutional and distributive The existence of a relationship between the economic and political instability of oil-exporting nations and the existence of weak institutions has been a theme studied in the Political Economy literature for several decades. Both the structuring of the State and the distributive political arrangements built under the aegis of an oil-dependent model would have tightened the possibilities of choice for these countries, helping to explain their trajectories. Using neoinstitutionalist approaches 
(KARL, 1997; ROSS, 2015), we seek to show how the administration of economic problems in petro-states depended on a set of incentives and rules that guided political actors, decisively affecting the results achieved. In this sense, the paper sought to analyze the impact of the redistribution of oil revenues in federations such as Brazil, Argentina, Mexico, Canada, United

States, Russia, India, Nigeria and Australia to understand whether greater decentralization would help to combat or aggravate the problems arising of the Natural Resource Curse. Instead of economic growth and income distribution, when poorly managed and distributed, oil resources would lead to rentier behavior patterns, fiscal lack of control, reduction of economic diversification, aggravating inequality, corruption and possibly leading to, at the limit, authoritarian exits and armed conflicts.

\section{Introdução}

A relação entre a abundância de recursos naturais e o desenvolvimento econômico não é uma questão trivial. Estudos mostram a existência de uma correlação positiva entre a performance econômica instável de países produtores de petróleo e a existência de problemas políticos, como instituições fracas, corrupção e desvios de recursos (AHMED, 2008; AUTY, 2001; COLLIER E HOEFFLER, 1998; EIFER, 2003). A centralidade do petróleo na matriz energética mundial desperta interesse por parte da academia, de governos e do setor privado (KARL, 1997; ROSS, 1999; GALL, 2006; LARSEN, 2004; ROSSER, 2006; ROSS, 2008; YERGIN, 2010). Recurso energético vital, ele exige domínio tecnológico e uso intensivo de capital para ser explorado, refinado, transportado e distribuído. Por um lado, as reservas de petróleo podem ser uma bênção para os países que as possuem em grandes quantidades, como a Arábia Saudita e a Noruega. Elas ajudam a desenvolver várias regiões do território nacional, aumentar a renda, elevar a arrecadação do setor público, ampliar investimentos e melhorar, de maneira geral, os padrões de vida da população. Por outro, ao ser mal geridas, também pode ser uma maldição, gerando problemas econômicos, sociais, políticos, ambientais e institucionais (SACHS, 1995; AHMED, 2008; ROSS, 2015).

Por que alguns países foram bem-sucedidos em lidar com o problema da maldição do petróleo e outras fracassaram ao fazê-lo? Existe alguma relação entre a centralização e a descentralização das rendas petroleiras 
e a habilidade dos Estados produtores de petróleo de se blindarem contra os efeitos nefastos da maldição dos recursos naturais? Este trabalho se propõe a discutir a maldição dos recursos naturais na perspectiva da redistribuição das rendas do petróleo em alguns dos grandes Estados federais que produzem ou exportam petróleo. As petrofederações são considerados Estados organizados sob a forma federal de governo e que possuem economias com diferentes graus de dependência em relação ao petróleo. Segundo Costa (2007: 173), o termo federalismo pode ser usado para denominar o conjunto de ideias inerentes à organização do Estado surgida no final do século XVIII, com a formação de um novo país, os Estados Unidos da América. Institucionalizado na Constituição norte-americana de 1787, o federalismo se tornou uma das mais originais contribuições da modernidade para a organização racional e eficaz do poder nos Estados de grandes dimensões continentais, múltiplas diferenciações étnico-culturais e assimétricos níveis regionais de desenvolvimento.

A segunda seção do trabalho discute o fenômeno da Maldição dos Recursos Naturais e suas consequências danosas para os petro-Estados. A seção trata da experiência de países que conseguiram estabelecer modelos de exploração do petróleo mais sustentáveis, como Canadá e Austrália. A terceira seção aborda as diversas experiências de Estados federais que possuem economias voltadas, em maior ou menor grau, à exploração do petróleo, bem como os diversos arranjos distributivos das rendas petroleiras neles existentes. Com relação ao tratamento federativo da questão do petróleo, há diversas experiências internacionais estudadas pela literatura. Este trabalho teceu algumas comparações entre nove casos: Brasil, Argentina e México, na América Latina; Canadá e Estados Unidos, na América do Norte; Rússia, Paquistão e Índia, na Ásia; Nigéria, na África; Austrália, na Oceania. A seleção dos casos procurou atender ao critério da diversidade geográfica e histórico-institucional, buscando entender as semelhanças e diferenças à luz de desafios impostos pelos problemas advindos da Maldição dos Recursos Naturais em economias desenvolvidas e em desenvolvimento. 


\section{A Maldição dos Recursos Naturais nos petro-Estados}

Um elemento importante da trajetória dos grandes países produtores e exportadores de petróleo, como Arábia Saudita, Rússia, México, Venezuela, Nigéria, Argélia, Irã e Indonésia, se relaciona com o papel desta commodity na estruturação do sistema econômico e da organização estatal destes países (KARL, 1997). Assim como nos petro-Estados o petróleo desempenha o papel de variável central no desenvolvimento nacional, nas petrofederações a indústria extrativa petrolifera, pelo seu tamanho em relação à economia, cumpre uma função primordial para o desenvolvimento nacional e gera grandes desafios relacionados à distribuição das rendas por ele geradas para os entes subnacionais. Os aumentos dos preços do petróleo na última década, alcançando patamares acima de U\$100,00, levaram diversas federações a rediscutir a distribuição das rendas (ROSS, 2015). De um lado posicionaram-se os defensores de critérios mais justos e equânimes para equilibrar o acesso às receitas por parte dos entes federados. Do outro lado, os que postulavam a necessidade de concentração das receitas extraordinárias nas mãos do governo central, visando objetivos de estabilização e de poupança intergeracional. Em países que experimentaram alto grau de centralização, negligenciando os impactos da atividade petrolífera sobre os entes locais, o problema da repartição dos recursos do petróleo se tornou até mesmo uma alavanca para a ocorrência de conflitos, decorrência daquilo que a literatura denomina de Maldição dos Recursos Naturais (SHAFER, 1994; EIFER, 2003; ROSS, 2015).

A explanação econômica mostra que a lógica da exploração petroleira desmobiliza as classes produtivas autônomas e expande a jurisdição estatal sobre a economia, gerando desigualdades estruturais permanentes. A explicação para o atraso econômico dos países exportadores de commodities se baseia na ocorrência de dois fenômenos inter-relacionados, um político e o outro econômico: a Maldição dos Recursos Naturais e a Doença Holandesa. A Maldição dos Recursos Naturais (Resource Course) é a tendência dos países com grandes reservas de recursos naturais de permanecerem num estágio inferior de desenvolvimento em relação aos que não os possuem em abundância (HUMPHREYS, SACHS E STIGLITZ, 2007). A Doença Holandesa, por sua vez, é um fenômeno causado pela rápida entrada de 
grandes quantidades de moeda estrangeira na economia nacional, levando à apreciação do câmbio e à perda de competitividade de setores industriais (ROSS, 1999).

A explicação para a Maldição dos Recursos Naturais residiria, principalmente, na apropriação das riquezas geradas pelos recursos naturais por elites predatórias que se aproveitam da fraqueza institucional desses países para incentivar comportamentos rentistas. A abundância de recursos naturais teria ainda uma correlação direta com a existência de governos predatórios e com a probabilidade de ocorrência de guerras civis, reduzindo as chances de os países pobres com abundância de recursos se tornarem mais desenvolvidos e estáveis (COLLIER e HOEFFLER, 1998; ROSSER, 2006). Já a Doença Holandesa (Dutch Desease) foi um fenômeno observado na economia da Holanda, no final dos anos 1960, logo após a descoberta de grandes reservas de gás natural (AHMED, 2008: 165). ${ }^{1}$ A decisão de explorar rapidamente esse recurso mineral elevou em demasia os salários do setor extrativista e de atividades conexas, provocando uma migração de mão de obra. Dado o influxo de moeda forte com o aumento das exportações, a valorização do florim em relação ao dólar reduziu a competitividade da agricultura e do setor de manufaturas (ROSSER, 13-14; KARL, 1997: 5). ${ }^{2}$

O fato de as rendas do petróleo pertencerem ao Estado também pode ter relação com a existência de estruturas governamentais inchadas, disfuncionais e propensas a gastar além dos limites de suas receitas (ROBINSON, TORVIK e VERDIER, 2005). Historicamente mal geridos, os recursos podem ser facilmente manipuláveis por burocratas e por políticos para o alcance de objetivos impopulares, controversos ou ilegais. Para Moreno, a abundância gera altos níveis de corrupção e desestimula o reforço dos di-

\footnotetext{
1 "Apesar de ser mais comumente usado em referência à descoberta de recursos naturais, o conceito de Doença Holandesa também pode referir-se a qualquer desenvolvimento que resulte em um grande fluxo de entrada de moeda estrangeira, incluindo aumentos repentinos de preços dos recursos naturais, assistência internacional ou investimentos estrangeiros volumosos" (NEVES, 2010: 107).

${ }^{2}$ Nesse sentido, a Doença Holandesa gera um efeito triplo na economia: (i) acelera a realocação de fatores de produção (capital e trabalho); (ii) expande a entrada de recursos financeiros que se convertem em moeda nacional, podendo gerar inflação; (iii) leva ao declínio de setores econômicos não relacionados com os recursos naturais, trazendo excessiva especialização (LARSEN, 2004).
} 
reitos de propriedade (2009). Ao gerar margens de lucro levadas, os recursos financeiros advindos da comercialização de diamantes na África possibilitam, por exemplo, o financiamento de milícias privadas, de gangues criminosas ou de exércitos rebeldes para garantir o retorno dos investimentos (ROSSER, 2006). Na ótica de Furtado, países especializados na exploração de recursos naturais, as sociedades passaram a viver das riquezas que herdaram como "dávida", pois "nasceram sobre uma mina de ouro". O problema é que as riquezas naturais podem trazer prosperidade financeira no curto prazo, mas levar ao declínio das atividades econômicas em outros setores, particularmente os orientados para a exportação (FURTADO, 1995, 40 apud AHMED, 2008: 168).

O fato de países como Venezuela, Argélia, Equador, Irã e Zâmbia terem fracassado na transformação de suas riquezas em desenvolvimento sustentável não constitui uma coincidência de equívocos apenas administrativos. Seus problemas econômicos e políticos têm um padrão estrutural e determinista mais profundo. ${ }^{3}$ Enquanto o fluxo de petróleo para o exterior supriu o Estado com receitas abundantes, o modelo rentista produziu crescimento, mas ocultou inúmeras distorções e desperdícios. A excessiva concentração de riquezas nas mãos de um Estado altamente politizado obliterou, por exemplo, o aperfeiçoamento das instituições e dos mecanismos de mercado (PRZEWORSKI, 1998). Ao invés de fomentar a confiança, a cooperação e a concorrência, o modelo rentista movido pelo petróleo em nações com grande abundância de reservas como a Venezuela converteu o Estado numa espécie de "feiticeiro magnânimo". Nessa atmosfera de possibilidades infinitas, os atores políticos podiam ser seduzidos e cooptados; os bens materiais, comprados ou produzidos a qualquer custo; as reformas econômicas e administrativas, substituídas pela postergação de ajustes impopulares (GALL, 2006a).

Em teoria, os países poderiam mitigar esses problemas, reforçando a blindagem da economia contra as vicissitudes dos mercados internacionais, fortalecendo as instituições e mantendo comportamentos fiscais pru-

\footnotetext{
${ }^{3}$ Kenneth Kounda, ex-presidente da Zâmbia, sintetiza a lógica intrínseca à Maldição dos Recursos Naturais: "We are in part to blame, but this is the curse of being born with a copper spoon in our mouths" (ROSS, 1999).
} 
dentes, caso, por exemplo, da Noruega (ROSS, 307). Enquanto, nas últimas décadas, Botswana, Chile, Malásia, Omã e Tailândia conseguiram driblar os efeitos mais destrutivos da Maldição dos Recursos Naturais, Venezuela, Argélia, Nigéria, Irã, Equador, México, Zâmbia e muitos outros não foram capazes de fazê-lo. De acordo com Robinson (2005: 27), o que diferencia essas duas categorias de nações não são os tipos de recursos naturais que exploram nem a quantidade de riquezas que possuem, mas a qualidade das instituições e das escolhas políticas realizadas em momentos críticos. Numa visão simplificada, a ausência de instituições fortes leva os políticos a acelerar a exploração dos recursos naturais para aumentar as suas chances de permanência no poder por longo período. Isso reduz drasticamente a qualidade do gasto público e faz proliferar os comportamentos rent-seeking. A distribuição ineficiente dos recursos, o clientelismo e os desperdícios contaminam a eficiência do resto da economia, comprometendo o crescimento de longo prazo (ROBINSON, 2005: 29).

Ao explicar o impacto dos booms nos países exportadores de petróleo, especialmente no que concerne às mudanças que ocorrem dentro dos Estados, Karl (1997), enfocou as complexas interações históricas entre desenvolvimento econômico e instituições politicas para tentar entender o que ocorreu nesses países. A comparação entre as bonanças petroleiras de 1973-74 e 1979-80 com a descoberta de imensas quantidades de ouro e prata nas colônias espanholas do século XVI e XVII, na ótica de Karl, é bastante pertinente, pois foram duas extraordinárias experiências de rápida acumulação de riquezas que mudaram a economia política internacional. Enquanto a riqueza dos metais levou ao esplendor o sistema econômico mercantilista e à expansão do império espanhol, as rendas do petróleo forneceram aos países produtores um poder econômico que jamais sonhavam deter. A diferença fundamental entre os dois casos, de acordo com Karl, foi o tempo decorrido entre o esplendor, o declínio e a ruína. Na Espanha seiscentista, um século; nos países exportadores de petróleo, uma década (KARL, 1997: 33).

Tanto na Espanha quanto nos países em desenvolvimento exportadores de petróleo, as rendas minerais vindas do exterior eram diretamente canalizadas para os erários públicos. A inflação dos objetivos das elites 
produziu uma expansão descontrolada dos gastos, superaquecimento da economia, elevação dos preços e salários e desorganização da produção. Em ambos os casos, os governos ignoraram os sinais de degeneração das estruturas econômicas e políticas e não fizeram os ajustes necessários para reorganizar as finanças e a economia em tempo hábil (KARL, 1997: 40-41). Nesse diapasão, o problema dos incentivos ajuda a explicar a coincidência de erros. Gastar as riquezas proporcionava recompensas e resultados políticos imediatos, enquanto a coerência administrativa, a racionalidade econômica e a prudência fiscal só teriam seus benefícios percebidos no longo prazo. Ao invés da lenta, gradual e paciente construção da autoridade estatal, optou-se pela compra de lealdades, pelo estabelecimento de clientelas, pelo financiamento de estilos de vida luxuosos e pela desmedida expansão jurisdicional, escolhas financiadas por um longo periodo de tempo (KARL, 1997: 41-42).

Para Karl, a extração de recursos de um único setor para financiar a máquina pública dos petro-Estados debilita a autoridade estatal, aumenta as chances de captura do Estado por interesses privados e desvia o curso da ação governamental para um padrão irracional, fragmentado e incoerente. Ou seja, a dependência das commodities pode comprometer quatro componentes simbólicas da soberania estatal: (i) a autoridade de criar, implementar e reforçar as decisões coletivas; (ii) o poder de fazer valer as normas jurídicas dentro do território; (iii) o exercício eficaz da coerção sobre a população; (iv) a habilidade de controlar, alocar e empregar eficazmente os recursos em serviços públicos e em programas de desenvolvimento (KARL, 1997: 45). Isso explicaria as semelhanças entre os países exportadores de petróleo no que diz respeito à capacidade estatal, às decisões políticas, aos comportamentos dos burocratas e à performance das economias.

Os petro-Estados são especialmente propensos à expansão desmedida da jurisdição e à externalização do poder, porém mal-sucedidos no aprofundamento e institucionalização da autoridade. A coincidência entre o processo de construção estatal e a dependência de commodities moldou o comportamento rentista dos agentes privados, a divisão institucional do setor público e as políticas de tributação, administração e repartição de recursos. Tais constrangimentos reduziram as margens de manobra da eco- 
nomia e produziram um ciclo retro-alimentador de interesses que perpetuaram a rigidez das instituições. Assim, a aguda dependência em relação a um único recurso tornou os Estados extrativistas altamente vulneráveis às vicissitudes do comércio internacional de commodities e às instabilidades econômicas externas (KARL, 1997: 46-47). ${ }^{4}$

Nas palavras de um estudioso do assunto, "o petróleo coloca um pote de ouro no fim do arco-íris, mas semeia o caminho até ele com minas" (SHAFER, 1987 apud KARL, 1997: 54). A mudança do modelo de desenvolvimento dos petro-Estados tem se revelado uma tarefa complexa. A dificuldade maior reside em desatrelar as escolhas dos incentivos inerentes ao processo de petrolização. A incapacidade de produzir coesão burocrática impede o exercício da autonomia estatal e amplia o fosso entre uma jurisdição estatal expandida, movida a petrodólares, e uma autoridade atrofiada, incapaz de implementar políticas públicas que produzam estabilidade. A distância entre a jurisdição e a autoridade deita raízes no atraso do processo de modernização institucional (KARL, 1997: 58-59). Nessa direção, o processo de descolonização, independência e afirmação da soberania dos petro-Estados se deu através de caminhos que dispensaram a conexão entre instituições tributárias típicas do processo clássico de state building (KARL, 1997: 60).

Os petro-Estados focaram sua capacidade de arrecadação, monitoramento e regulamentação exclusivamente no setor exportador. A sociedade também se acomodou com um padrão de gestão governamental que procurava evitar decisões domésticas impopulares concernentes à distribuição das rendas petroliferas. Num outro plano, a força do estatismo ajudou a centralizar as decisões referentes à alocação de recursos no poder Executivo, mas obstruiu o desenvolvimento de mecanismos de controle nos parlamentos, nos tribunais e na sociedade. As ideologias nacionalistas de variadas colorações, por seu turno, levaram ao ápice a demanda por bens e serviços públicos e o tamanho das máquinas públicas. Conforme o petróleo

${ }^{4} \mathrm{O}$ fato de a economia basear-se na exploração de um recurso finito também impõe dilemas sobre a conveniência de extraí-los num horizonte temporal mais curto ou deixá-los armazenados no subsolo para as gerações futuras. Ou ainda sobre a eventualidade de gastar as rendas ou poupá-las para os dias mais dificeis. Essas decisões dependem das taxas de retorno esperadas, das estimativas de esgotamento dos recursos e, principalmente, dos constrangimentos institucionais existentes (KARL, 1997: 48). 
alavancava a centralização do poder, os petro-Estados foram se tornando estruturas gigantescas, porém desprovidas de coordenação, coesão, coerência e autonomia (KARL, 1997: 59). A concentração de recursos e de poderes desequilibrou a relação entre o Executivo, o Legislativo e os governos subnacionais. Dessa forma, os aumentos de despesas, o déficit público e endividamento desorganizam a gestão macroeconômica e empurram a resolução dos problemas para o futuro (KARL, 65-66).

Os Estados que dependem das rendas extraordinárias do petróleo também dispensam a contribuição de sistemas tributários mais abrangentes para organizar suas finanças e não criaram uma cultura política capaz de estimular o controle dos gastos públicos e o comportamento dos governantes pelos cidadãos. A distribuição dos recursos se realizou de maneira discricionária, arbitrária e, muitas vezes, irracional. Esse conjunto de constrangimentos institucionais impediu a mobilização do Estado para fora da rede de obrigações clientelísticas tradicionais, o emprego de recursos em escala nacional, a separação entre as esferas pública e privada e o desenvolvimento de mecanismos de accountability (KARL, 61). ${ }^{5}$ Consequentemente, a ausência de normas e freios à ação do Estado, muitas vezes controlado por um único indivíduo ou por um pequeno grupo de oligarcas, politizou todas as esferas decisórias. Em linhas gerais, Karl (1997) explica a dinâmica social, econômica e política que aprisiona os países exportadores de petróleo no chamado "paradoxo da riqueza". Sua abordagem permite esclarecer como as decisões são tomadas diante de um conjunto de instituições historicamente construídas, moldando um padrão comportamental que se estende ao conjunto dos países analisados e que explica os resultados semelhantes alcançados.

\section{Escapando da maldição dos recursos naturais}

Há uma grande variação de experiências de nações que conseguiram escapar da sina de corrupção, rent-seeking, pobreza, violência e predação. Os países em desenvolvimento com instituições de boa qualidade, definidas

5 Assim como a personagem principal de "Gulliver's Travels", do romancista irlandês Jonathan Swift, os petro-Estados se tornaram verdadeiros gigantes cercados por milhares de interesses "lilliputianos" rentistas (KARL, 1997). 
em termo de Estado de Direito, autonomia da burocracia, baixo nível de corrupção, respeito aos direitos de propriedade e cumprimento dos contratos, alcançaram maiores taxas de investimento e poupança do que os paises bem mais ricos em recursos naturais, mas com instituições fracas. O Chile, na América Latina, a Malásia, na Ásia, e Botswana, na África, têm tido um bom desempenho em gerir suas riquezas nas últimas décadas graças a esse diferencial institucional (ROSSER, 2006). Segundo Eifert et alli. (2003), as democracias maduras tiveram um desempenho melhor em termos de administração das rendas do petróleo do que as autocracias, pois seus altos níveis de transparência, accountability e proteção aos direitos civis e políticos se traduziram numa maior capacidade de tomar decisões de longo prazo e implementar políticas econômicas mais coerentes (ROSSER, 2006). A experiência da Noruega permite mostrar ainda a trajetória alternativa de um país econômica e socialmente desenvolvido na qual a exploração do petróleo não coincidiu com o processo de formação das estruturas institucionais do Estado.

Para Larsen, a administração dos recursos petrolíferos na Noruega nas últimas quatro décadas não foi algo trivial (2004). A nação escandinava tem sido objeto de numerosos estudos acadêmicos por parte de economistas e cientistas políticos porque soube combinar a exploração dos seus hidrocarbonetos com a manutenção da estabilidade macroeconômica e política (EIFERT et alli, 2003: 5-6). Na década de 1960, era um país escassamente povoado e pouco urbanizado que compartilhava com outros países escandinavos, como a Suécia e a Dinamarca, uma trajetória de desenvolvimento econômico-social quase idêntica e uma herança histórica, política, lingüística e cultural comum (LARSEN, 2004: 8). A economia era mais diversificada, com crescimento estável, baixo desemprego, bons sistemas de educação, saúde e previdência social, renda per capita elevada. Ademais, o sistema tributário era mais desenvolvido, com uma capacidade maior de extração de recursos (KARL, 1997: 213-214).

O planejamento cuidadoso da exploração marítima, a extração gradual do óleo, o recebimento de quantidades mais modestas de recursos e a prudência fiscal foram alguns dos comportamentos verificados naquele país. A jurisdição estatal bem definida, o corporativismo de corte pluralis- 
ta e a visão igualitária de uma sociedade acostumada a respeitar regras e procedimentos também amorteceram os conflitos e contiveram o comportamento rent-seeking (KARL, 1997: 215-217). Os setores laborais e empresariais se mostraram igualmente conscientes da necessidade de preservar a diversificação da economia. Para os burocratas, o petróleo cumpriria um papel apenas marginal numa economia que já era diversificada, próspera e saudável. A maior participação do Estado na alocação das rendas do petróleo levou à ampliação da jurisdição do setor público, diferentemente dos casos da província canadense de Alberta e do estado norte-americano do Alasca, onde a distribuição dos recursos ainda é feita com base em critérios individualistas (EIFERT et alli, 2003: 5-6).

O objetivo do governo norueguês era atrelar os avanços da exploração dos poços do Mar do Norte ao desenvolvimento de tecnologias, infraestruturas, capacidades, expertises e regras para disciplinar a economia do petróleo. ${ }^{6}$ Ainda nos anos 1960, houve longo debate no parlamento norueguês e na imprensa acerca dos custos e benefícios envolvidos na exploração dos gigantescos campos da plataforma continental. As empresas petroliferas, os empresários, os sindicatos e os países ocidentais consumidores se posicionaram favoravelmente à exploração, ressaltando os seus aspectos positivos: a aceleração do crescimento, a obtenção de dividendos fiscais e a possibilidade de expansão do estado de bem-estar social. De outro lado, a indústria da pesca, os ambientalistas e os agricultores salientaram o lado negativo: a possibilidade de ocorrência de Doença Holandesa, os impactos ambientais e os riscos de comportamentos rent-seeking (KARL, 1997: 218219). Em 1974, o parlamento decidiu levar adiante a exploração do petróleo com cautela, prudência e planejamento.

Essa combinação de controle político, expertise burocrática e preocupações sociais mais amplas impediram desvios súbitos de rota, dissolvendo os riscos de corrupção e amortecendo o impacto do primeiro boom do petróleo (1973-1974) sobre a economia e sobre o regime político. Ao invés de

${ }^{6}$ Nesse sentido, reforçou-se a profissionalização dos quadros estatais, cuidou-se da reorganização do Ministério da Indústria, demarcou-se o papel das empresas estrangeiras e criou-se uma nova empresa estatal, a Den Norske Stats Oljeselskap A/S (Statoil). Ao mesmo tempo, os direitos de prospecção foram concedidos à Norsk Hydro e à Saga Petroleum, com alguma participação do Estado. 
distribuir os recursos que entravam nos cofres do Estado para projetos de retorno duvidoso, decidiu-se pela aplicação de mais da metade deles na expansão e modernização da própria atividade petrolífera. O Estado buscou, assim, proteger sua base fiscal, moderar o aumento de gastos, não endividar-se e poupar parte dos recursos para momentos futuros de escassez (KARL, 1997: 219-220).

Os governos noruegueses conseguiram prever cenários, tomar medidas preventivas e combinar criativamente os recursos disponiveis para administrar os problemas econômicos, politicos e institucionais inerentes à petrolização do país. A política industrial ativa contribuiu para o acúmulo de know-how e a manutenção de uma base exportadora diversificada. O Estado norueguês driblou o efeito spillover-loss (perda de externalidades positivas) direcionando a maioria dos recursos que entraram nos cofres públicos para a melhoria do capital humano, a requalificação da mão-de-obra, a ampliação dos investimentos em centros de pesquisa e o acúmulo de expertises através do aprendizado de seus pesquisadores no exterior (LARSEN, 2004: 13-14). Ademais, a política fiscal disciplinada permitiu a antecipação do pagamento da divida externa, o estabelecimento de um fundo soberano no exterior e o fortalecimento das políticas anticíclicas. ${ }^{7}$ Criado em 1990, o Fundo do Petróleo (Government Petroleum Fund) foi especialmente concebido para proteger a economia da propensão governamental de elevar rapidamente os gastos públicos. Seu propósito era investir no exterior os recursos arrecadados com impostos, royalties, licenças e lucros do petróleo. Consequentemente, economia foi blindada contra os excessos da demanda, a apreciação exagerada do câmbio e a perda de competitividade das exportações (LARSEN, 2003: 13-14).

Se por um lado o Fundo de Petróleo da Noruega foi capaz de poupar boa parte da renda auferida com a extração do petróleo, por outro dissemi-

\footnotetext{
7 O Fundo foi pensado principalmente para preservar as riquezas nacionais para as futuras gerações quando a prospecção começasse a entrar em declínio, sendo administrado pela Norges Bank Investment Management (NBIM), uma divisão do Banco Central da Noruega. Em dezembro de 2010, suas reservas disponiveis foram calculadas em US\$ 525 bilhões. Desde 2007, o Fundo está autorizado a investir 60\% dos seus recursos em portfólios de ações no mercado mundial de capitais. Segundo previsões realistas do Ministério das Finanças, o Fundo Global pode ultrapassar o montante de estabilizar-se em torno do patamar de US\$ 1,2 trilhão em 2030 (ROSS, 2015).
} 
nou a sensação de que as imensas riquezas poupadas, quando alcançassem um volume considerável, deveriam ser distribuídas entre os cidadãos. Em virtude da enorme quantidade de recursos disponiveis em proporção à pequena população norueguesa, que não ultrapassa 5 milhões de habitantes, um dos principais pontos em discussão é a possibilidade de o governo poupar menos para o futuro e elevar os gastos públicos. Em 2001 foi criada uma "regra de ação", um mecanismo de política fiscal que permite que se empreguem, domesticamente, apenas os rendimentos anuais do fundo. A regra orçamentária prevê que apenas um máximo de 4\% do total dos ativos seja alocado no orçamento anual norueguês. Essa providência não tem impedido que os governos ultrapassem a dosagem recomendada.

Como se pode verificar, após a descoberta do petróleo em sua costa, a Noruega decidiu manter políticas econômicas e energéticas diferenciadas: soube, principalmente, poupar e gastar, com prudência, as rendas do petróleo. A consistência das instituições conteve os excessos da exuberância irracional criada pela atmosfera de bonança, ajudando a explicar o sucesso do seu modelo. A preocupação norueguesa era preservar as conquistas democráticas e igualitárias com políticas capazes de minimizar os custos econômicos, sociais e políticos da exploração acelerada do petróleo.

\section{Centralizar ou descentralizar as rendas do petróleo?}

Przeworski (1998) mostra que a descentralização de poder está positivamente associada à busca da eficiência na alocação de recursos públicos e à maior democratização do exercício da atividade governativa, racionalização da implementação do gasto público e maior controle sobre a administração do Estado. Sob a ótica da eficiência, a descentralização permite o emprego de soluções não-padronizadas de gestão de politicas públicas e um tratamento diferenciado em função de particularidades regionais e locais, aumentando as chances de adequação da escala de provisão de um bem ou serviço ao tamanho da área geográfica delimitada e de seu melhor ajustamento às preferências da população local (CLARCK, 1991). Além disso, a fragmentação do poder político-administrativo de uma esfera central suprema para um conjunto de entes subnacionais incentivaria a participação nos processos decisórios (PAULA, 2005). 
Dentre os limites políticos e operacionais da descentralização, destacam-se os riscos de ineficiência na alocação de recursos por parte dos gestores locais e as dificuldades inerentes à implementação de políticas públicas, muitas vezes sem a devida presença de institucionalidade e profissionalização burocrática mínimas. Isso se reflete na baixa capacidade de desempenho operacional desses agentes, na ineficácia dos procedimentos administrativos utilizados, na deficiência dos instrumentos e recursos mobilizados e, por conseguinte, nos resultados insuficientes alcançados. Portanto, não se pode conceber a descentralização sem a construção de capacidade estatal durável e efetiva nos níveis subnacionais, capaz de impedir a pulverização de recursos escassos, ineficiências custeadas com subsídios do poder público, concentração de renda e aumento da corrupção. Outro problema que permeia a descentralização é a ausência de mecanismos efetivos de controle social, um fator que compromete a separação entre interesse público e privado e aumenta as chances de captura da administração por interesses particularistas locais.

Gobetti (2011) buscou mapear as principais experiências internacionais atinentes à repartição dos recursos naturais nas petrofederações. Argentina, Austrália, Brasil, Canadá, Estados Unidos, Índia, Malásia, México, Nigéria, Paquistão, Rússia e Venezuela são alguns dos países produtores de petróleo que possuem forma federal de Estado. Nas federações mais antigas (caso dos Estados Unidos, Argentina, Austrália e Canadá), forjadas através da união de estados ou províncias (e, não menos importante, concebidas antes da descoberta do petróleo), o controle dos recursos do subsolo, de interesse apenas local era, inicialmente, dos entes federados. Posteriormente, parte da jurisdição foi transferida para os governos centrais. Por outro lado, em países como México e Venezuela, em que a descentralização foi tardia, os governos centrais passaram a concentrar maior poder sobre a exploração da riqueza mineral, com a repartição menor de recursos para os entes federados.

O critério principal para a definição da repartição das rendas, na maioria das federações, é o geográfico, o que muitas vezes leva ao risco de arbitrariedades na delimitação das adjacências de determinado campo petrolífero. Além de argumentos territoriais, a força regional, as regras cons- 
titucionais definidas e as tradições pretéritas importam nas escolhas de modelos distributivos. A questão do federalismo fiscal nas petrofederações, argumenta Gobetti, deve ser analisada numa perspectiva mais abrangente, de modo a contemplar o rol de tributos que incide sobre a cadeia produtiva do petróleo e os mecanismos vigentes de compartilhamento e distribuição horizontal das rendas. Nesse sentido, a maior parte das federações possui instrumentos limitadores do poder de tributação sobre a riqueza petróleo e a competição predatória entre unidades federativas, buscando compensar as desigualdades existentes através de transferências (GOBETTI, 2011: 15).

Inexiste um padrão federativo internacional para definição do controle e da divisão das receitas da exploração do petróleo. O Canadá, por exemplo, criou um sistema descentralizado, financiado pelo governo federal, que garante a todas as provincias um percentual mínimo de receitas a partir da divisão dos recursos, um mecanismo que não impede que as províncias produtoras obtenham dotações bem maiores que as demais. Embora decisões da Suprema Corte canadense dos anos 1980 tenham garantido a jurisdição federal sobre a produção, pressões provinciais levaram à celebração de acordo político que estabelece o direito de as unidades federadas cobrar impostos sobre atividades offshore. Considerando que a maior parte da produção é terrestre, as províncias são autônomas para cobrar royalties e impostos sobre a renda das empresas. A produção marítima também dá às províncias confrontantes o direito de cobrança de imposto de renda. Por sua vez, as províncias produtoras arrecadam recursos em volume maior (Alberta, principalmente), mas não recebem dinheiro do fundo de equalização e não contribuem para ele, obrigando o governo federal a compensá-lo. Assim, o sistema de compensações visa proporcionar um patamar mínimo de receitas às províncias, sem promover, de fato, a sua redistribuição.

Nos Estados Unidos, cerca de $75 \%$ da extração de petróleo é terrestre. Os estados, por sua vez, têm autonomia para a cobrança de royalties e imposto de renda próprio, incluindo metade da produção petroleira em territórios federais que a eles pertenciam anteriormente. A despeito de a produção offshore pouco beneficiar os entes da federação, o governo federal promove compensações através de programas governamentais específicos, algo diferente dos fundos de transferências existentes no país vizinho. No 
caso do Canadá e Estados Unidos, onde as economias são mais diversificadas, a maior descentralização na taxação da indústria petrolifera não gera tantas distorções como nas chamadas petrofederações, menos desenvolvidas e mais dependentes da exploração mineral. O México, por outro lado, é uma típica petrofederação, já que mais de um terço das receitas tributárias nacionais advêm da taxação do setor petrolifero e da estatal Petróleos Mexicanos (PEMEX). A petroleira repassa ao governo central mais de $60 \%$ de suas receitas e parte de seu lucro extraordinário quando os preços do barril do petróleo sobem. Parte desse montante é canalizado para um fundo de participação redistribuído entre as unidades federadas segundo critérios populacionais e de capacidade de geração de receitas. Na Venezuela, igualmente uma federação (ao menos no papel), cerca de $60 \%$ das receitas do governo dependem de repasses da Petroleos de Venezuela (PDVSA) ao governo central. Os fundos de participação interterritoriais são fortemente controlados pelo governo federal, bem com os recursos extraordinários da PDVSA, dando-lhe grande margem de manobra orçamentária (GOBETTI, 2011: 21-23).

Na Rússia, a descentralização da repartição de recursos estabelecida após o colapso do regime soviético foi revertida a partir de alterações constitucionais. Metade das receitas governamentais provêm do setor de hidrocarbonetos através de impostos sobre extração mineral e exportação. A partir de 2002, mudanças no marco legal reduziram de $60 \%$ para $0 \%$ o percentual distribuído aos governos regionais. O mecanismo equalizador das distorções é o imposto de renda pessoal e corporativo, que retorna à origem, favorecendo as regiões produtoras (GOBETTI, 2011: 16-19). Na Nigéria, o alto grau de centralização existente durante os primeiros anos pós-independência foi recentemente contestados por decisões legislativas que garantem maior distribuição entre as províncias produtoras e confrontantes. O governo federal retém $80 \%$ do lucro da exploração, mas compartilha parte da arrecadação segundo critérios de densidade populacional e de extensão territorial. De todas as federações, a nigeriana é a mais contenciosa e problemática na repartição dos royalties, com conflitos entre o poder central e as regiões produtoras do Rio Níger, que apesar de ricas em recursos minerais, apresentam um dos piores indices de desenvolvimento econômico e social do continente africano. Na federação paquistanesa, 
enquanto a propriedade é compartilhada entre os entes federados, ao governo central cabe gerir a exploração do petróleo, com a repartição das receitas exclusivamente entre as províncias. Na Malásia e Índia, enquanto a propriedade pertence aos Estados, o controle sobre a produção é federal, enquanto as receitas são compartilhadas entre todos. O governo central indiano detém $100 \%$ da arrecadação do petróleo produzido na plataforma marítima e metade dos royalties e lucros em campos terrestres. Os critérios de transferências são mais discricionários, definidos por uma comissão nomeada pelo presidente da República (GOBETTI, 23-27).

No caso do petróleo extraído no mar (plataforma continental), na maior parte das federações, o governo central detém a propriedade e o controle sobre os recursos. Brasil, Canadá e Nigéria são federações que possuem mecanismos de cessão ou compartilhamento das receitas obtidas com a exploração em alto mar. Na Argentina e Austrália, onde a propriedade das jazidas é federal, não há mecanismos de compartilhamento de rendas do petróleo extraído no mar entre os entes federados. Na Argentina, as províncias são autônomas para cobrar royalties sobre o petróleo extraído em terra, mas o governo central cobra impostos de exportação do barril do petróleo quando os preços ultrapassem os U\$ 42,00, arranjo que visa cobrir o déficit fiscal federal. Na Austrália, o regime de equalização garante, através de transferências governamentais, uma equiparação entre regiões produtoras e as demais. A Lei do Petróleo de 1967 e a Lei do Imposto sobre a Renda do Petróleo, de 1987, determinam que as receitas sejam são divididos com os Estados através da taxação sobre o óleo cru e a cobrança de royalties. Desde 1973, a federação australiana adota um regime de equalização entre capacidade de arrecadação e necessidades de gastos, promovendo a complementação e redistribuição de receitas. Dentre as federações analisadas, é a que adota o sistema mais autêntico de equalização, eliminando distorções fiscais e eventuais barganhas que decorreriam da concessão de benefícios e subsídios (GOBETTI, 2011: 23-27).

O modelo regulatório da indústria do petróleo no Brasil, instituído, em seus grandes marcos, a partir da Constituição de 1988, posiciona o país como uma das federações que possuem maior grau de centralização em 
relação à gestão das atividades petrolíferas. ${ }^{8}$ Reserva à União a propriedade sobre os recursos naturais da plataforma continental e da zona econômica exclusiva, o mar territorial e os recursos minerais, inclusive os do subsolo (art. 20, V, VI e IX da Constituição Federal). Prevê, ademais, a distribuição das receitas oriundas da exploração mineral com outros entes federados (art. 20, parágrafo $1^{\circ}$ ). Na reforma constitucional de 1995, a Constituição estabeleceu o monopólio da União nas atividades de pesquisa e lavra de jazidas, refino e importação e exportação de petróleo e seus derivados, bem como no transporte marítimo, ressalvando a possibilidade de contratação de empresas privadas ou públicas para estas atividades. ${ }^{9}$

As descobertas de abundantes jazidas de petróleo no litoral brasileiro na última década dividem opiniões. Se por um lado trouxeram esperança de aceleração do desenvolvimento e de superação dos velhos problemas sociais brasileiros, por outro mostraram os riscos do emprego inadequado das rendas proporcionadas pela exploração dessa riqueza mineral num país com um passado ainda recente de descontrole fiscal e monetário e com elevado grau de politização da gestão de empresas estatais. A corrupção na gestão da empresa Petróleo Brasileiro S.A. (Petrobrás) e os prejuízos apresentados pela petroleira estatal na manutenção de uma politica de congelamento de preços dos combustiveis mostram que a utilização discricionária e problemática das rendas do petróleo não é algo fora do radar da realidade brasileira.

${ }^{8}$ Embora se organize segundo a forma federativa de Estado desde a Proclamação da República, em 1889, e tenha na descentralização político-administrativa um dos pilares de sua Carta Magna (CF/1988), subsistem imensos problemas, falhas e lacunas concernentes aos mecanismos de articulação intergovernamental na Federação brasileira. Apesar da valorização das esferas regional e local, subjacente a uma descentralização de competências e recursos, a estrutura federativa brasileira ainda repousa sobre bases frágeis. Considerando o tamanho, a diversidade e a complexidade geográfica do país, um aspecto central para a compreensão dos rumos atuais do federalismo no Brasil é o tratamento que tem sido dado à repartição de recursos fiscais.

${ }^{9}$ No âmbito infraconstitucional, as Leis Federais 9.478/1997 e 12.351/2010 são os principais instrumentos que constituem o marco legal da indústria do petróleo no Brasil. A primeira define o estabelecimento e os objetivos do Conselho Nacional de Política Energética (CNPE) e da Agência Nacional do Petróleo (ANP), estabelecendo ainda um regime de concessões para a exploração da atividade petrolifera. A segunda estabelece as regras para a exploração dos campos descobertos na camada pré-sal, reservas de óleo localizadas no alto mar, abaixo de uma lâmina de água de dois mil metros e de três a quatro mil metros de subsolo marinho. 


\section{Considerações Finais}

$\mathrm{Na}$ perspectiva histórico-institucionalista, os petro-Estados compartilham a mesma trajetória da dependência. As semelhanças institucionais englobam a propriedade estatal das jazidas, a estruturas tributárias pouco capilares e a prevalência de interesses rentistas sobre as forças produtivas autônomas. A junção de poder altamente concentrado, riqueza inesperada e fraqueza do Estado agravaram a dependência das rendas minerais e incentivaram a reprodução de padrões de comportamento rent-seeking. Ao contrário do ilimitado poder e riqueza que imaginavam controlar para mudar seu destino, houve um estreitamento do espaço de manobra para redirecionar o curso da economia e evitar o colapso da autoridade estatal. Nessa linha, escolhas econômicas e politicas, balizadas pelas instituições, foram responsáveis pela ocorrência da Maldição dos Recursos Naturais em alguns deles.

Há uma correlação direta entre a expansão contínua das economias baseadas no setor do petróleo e a estabilidade de regimes e governos, democráticos ou autoritários. Os petro-Estados permaneceram politicamente estáveis enquanto os preços do petróleo cresceram ou declinaram lentamente, em termos reais. O ponto frágil do modelo são as oscilações bruscas dos preços para cima (que trazem expansão fiscal e dependência excessiva das rendas extraordinárias) ou para baixo (que evidenciavam a inviabilidade política de ajustes rápidos), com efeitos altamente disruptivos sobre a economia e o Estado

De acordo com Ross (2008: 22), o efeito da riqueza do petróleo varia de acordo com os regimes, o desempenho econômico e a qualidade das políticas públicas de cada país. As nações que experimentaram maior grau de instabilidade política (Irã, Nigéria e Argélia) foram as que mais rapidamente elevaram os seus gastos públicos. A Venezuela teve uma expansão fiscal maior, mas o impacto disruptivo do boom foi amortecido pelo pactualismo democrático vigente desde 1958. Os regimes baseados em personalismo autoritário, como o Irã, foram mais fortemente afetados, pois sua única fonte verdadeira de legitimação era o crescimento econômico. Na Nigéria, a fraqueza estatal, os comportamentos predatórios e as múltiplas rivalidades 
existentes entre grupos desestabilizaram todos os governos, evidenciando sua condição de Estado falido. Por outro lado, a experiência diferenciada da Noruega mostra como os regimes democráticos foram mais eficientes em amortecer os impactos disruptivos da petrolização, favorecendo o debate e a consulta entre as forças políticas (KARL, 1997: 232).

As democracias introduzem elementos de legitimidade e participação que ampliam os nexos entre Estado e sociedade, permitindo o constante escrutínio dos cidadãos sobre os políticos e os burocratas, a transparência e o controle das políticas públicas implementadas. Nas democracias, as transições de poder também se processam de um modo mais ordenado e previsível, diluindo tensões acumuladas sem abalar a estrutura institucional (KARL, 1997: 228-230). A possibilidade de construção de consensos numa sociedade democrática, informada e educada afasta a possibilidade de aventuras que possam ameaçar a estabilidade. Embora as autocracias também possam buscar implementar politicas de desenvolvimento a longo prazo, caso da Arábia Saudita e Indonésia, a falta de controle e transparência abre espaços para a corrupção e a ineficiência, dificultando a redução da dependência do petróleo.

A dependência da exportação de uma só commodity se traduz na incapacidade de direcionar o desenvolvimento para outros caminhos. A coincidência entre a exploração mineral e a formação dos Estados nacionais impactou de maneira profunda os grandes países exportadores de petróleo, moldando estruturas de escolha, comportamentos e vícios de origem (KARL, 1997: 237-238). O mapeamento das conexões entre capacidades estatais e commodities explica as razões de sucesso ou de fracasso das políticas perseguidas pelos exportadores de petróleo para transformar as riquezas em possibilidades concretas de desenvolvimento. Nesse prisma, o petróleo molda uma estrutura básica de incentivos que influencia as relações contratuais e os direitos de propriedade, a separação entre o público e o privado, as prerrogativas das agências governamentais, o sistema tributário, as preferências de gasto público, o modelo de inserção internacional e o caráter simbólico do Estado (Karl, 1997: 239).

Há lições fundamentais que os petro-Estados precisam assimilar para escapar da maldição dos recursos naturais. Primeiro, o previsível declínio 
da oferta de petróleo em algumas décadas é um alerta importante para que eles se preparem adequadamente para um futuro sem essa riqueza. Segundo, é perfeitamente viável conciliar a exploração de recursos naturais com desenvolvimento equilibrado e inclusivo, vide os exemplos da Noruega, Canadá, Austrália, Nova Zelândia, Zâmbia, Namíbia, Bostwana e Chile. Terceiro, é igualmente possivel que as nações prosperem mesmo sem possuir essas riquezas. Os casos do Japão e da Coréia do Sul provaram que a necessidade de superação dessa deficiência de recursos da natureza pode catalisar a construção de capacidades estatais fundamentais para o desenvolvimento de longo prazo.

Os principais problemas advindos da interação do petróleo com os petro-Estados requerem uma adequada capacidade de gestão macroeconômica e de cooperação internacional. Em primeiro lugar, é preciso controlar a demanda agregada e esterilizar os efeitos inflacionários da monetização das receitas petroliferas via controle fiscal e acúmulo de reservas no exterior. Em segundo lugar, os países produtores deveriam perseguir estratégias que visassem manter os preços do petróleo em níveis estáveis e não tão altos, reduzindo os incentivos para a entrada de novos produtores no mercado. Em terceiro lugar, deveriam fortalecer suas instituições políticas e buscar construir capacidades estatais mais abrangentes. O calcanhar de Aquiles é a necessidade de reforço de suas capacidades estatais, ponto superficialmente tratados pela agenda de reformas de mercado implementadas nos anos 90 (KARL, 1997).

Os economistas têm enfatizado a necessidade de esses países adotarem padrões macroeconômicos mais responsáveis, com menor grau de endividamento, acúmulo de superávits fiscais, criação de fundos de estabilização, controle da inflação e perseguição de taxas de câmbio mais competitivas. Ademais, a combinação de taxações mais modestas do setor do petróleo com medidas focadas na melhoria da administração tributária ajudariam a criar uma cultura que valorize a importância do pagamento de impostos. As pressões internas e externas podem criar constrangimentos que ajudam a fortalecer essas escolhas. No plano político, os países deveriam gradualmente construir instituições representativas mais democráticas. Nesse sentido, são evidentes as lacunas deixadas pelas reformas 
de mercado de primeira geração em países como Venezuela. Ao invés de enfraquecerem o Estado, elas deveriam ter ajudado a fortalecer as instituições, profissionalizar as burocracias, modernizar a regulação e incentivar a transparência (ROSSER, p. 25). Portanto, há um grande esforço de institucionalização a ser feito para a adoção dessas políticas.

Conforme foi visto na experiência da democracia norueguesa, as instituições foram capazes de encaminhar a petrolização da economia por caminhos previsíveis e controláveis. A probabilidade de comportamentos rent-seeking foi minimizada em virtude do sistema legal eficaz, das normas sociais bem enraizadas e da transparência das políticas públicas. A movimentação dos fatores de produção foi evitada através de mecanismos de coordenação de renda acordados entre os setores empresariais e trabalhistas, facilitando as negociações e evitando a migração de mão de obra. O efeito-gasto foi contido porque o governo blindou a economia contra o risco de monetização excessiva, introduzindo medidas de disciplina fiscal. Por fim, o efeito spillover-loss foi pequeno, pois as perdas de competitividade na indústria foram compensadas por ganhos em setores de alta tecnologia na exploração off-shore e por estímulos governamentais à capacitação da mão-de-obra. Finalmente, o acúmulo de recursos no fundo de estabilização tem gerado pressões para o aumento dos gastos públicos à medida que a população envelhece e a exploração mineral tende a declinar.

As experiências internacionais mostram as diferentes soluções dadas à administração e repartição das rendas petroliferas em federações como Estados Unidos, México, Canadá, Argentina, Brasil, Venezuela, Rússia, Índia e Malásia. A exploração mineral impactou de maneira profunda as chamadas federações, moldando estruturas governamentais e comportamentos que se reproduziram ao longo de décadas. A literatura sugere, entretanto, que as receitas do petróleo deveriam ser centralizadas para proporcionar uma gestão mais eficaz dos recursos em países sem estruturas institucionais robustas, tendo em vista a falta de capacidade estatal dos governos subnacionais e a necessidade de inclusão das rendas numa coordenação macroeconômica integrada. Uma lição das experiências internacionais de Estados produtores e exportadores de petróleo como Noruega, Austrália e Canadá é a necessidade de criar mecanismos mais transparentes e respon- 
sivos para a gestão dos recursos fiscais proporcionados pela exploração do petróleo. A ânsia em gastar os royalties de qualquer maneira abre perigosas brechas para a irresponsabilidade fiscal e para a perda da eficiência administrativa.

Em suma, fatores históricos, políticos, econômicos e institucionais se inter-relacionam para explicar as escolhas e as trajetórias de desenvolvimento dos países que se especializaram na extração e comercialização do recurso energético não-renovável mais estratégico da sociedade moderna. Tal como a Espanha metropolitana se beneficiou dos booms do ouro e da prata e depois se tornou um dos países mais pobres e atrasados da Europa Ocidental, a riqueza fácil dos países em desenvolvimento exportadores de petróleo os colocou numa trajetória problemática de dependência extrema. O depoimento de um ex-titular do Ministério do Petróleo da Arábia Saudita, Sheik Ahmed Yamani, resume o dilema vivido por esses Estados: "'All in all, I wish we had discovered water" (KARL, 1997). Nas palavras de Terry Lynn Karl, "this is the paradox of plenty. But it is not inevitable. Paradoxes can be resolved and development trajectories can be altered, even if it takes decades or sometimes centuries."

\section{Referências}

ABRÚCIO, Fernando Luiz (2006). Para além da descentralização: os desafios da coordenação federativa no Brasil. In: Fleury, Sônia (org.). Democracia, descentralização e desenvolvimento: Brasil e Espanha. Rio de Janeiro: Editora FGV, p. 78.

AFONSO, José (1996). Descentralizar e depois estabilizar: a complexa experiência brasileira. Revista do BNDES, Rio de Janeiro, vol. 3(5), p. 31-62, junho.

AHMED, Abdelkader Sid (2008). Celso Furtado e o desenvolvimento a partir da exportação de recursos naturais não renováveis. In: Celso Furtado. Ensaios sobre a Venezuela: subdesenvolvimento com abundância de divisas. Rio de Janeiro: Contraponto; Centro Internacional Celso Furtado.

AUMAITRE, José Vicente Carrasquero (2002). ९Venezuela: Democracia en crisis? Rio de Janeiro: Fundación Konrad Adenauer, N. 9. 
AUTY, R (2001). Introduction and Overview, in R. Auty (ed.), Resource Abundance and Economic Development. Oxford: Oxford University Press, 2001: pp. 3-6.

BROSE, Markus (2002). Descentralização e good governance: como aperfeiçoar o desempenho dos governos locais? RSP, ano 53, n. 3, Jul-Set 2002, p. 95.

CLARCK, David (1991). Introdução à geografia urbana. Rio de Janeiro: Bertrand Brasil, p. 127-179.

COLLIER, P.; HOEFFLER, A (1998). On Economic Causes of Civil War. Oxford Economic Papers No 50, pp. 563-73.

COSTA, Valeriano. Federalismo (2007). In: AVELAR, Lúcia; CINTRA, Antonio Octávio Cintra. Sistema Politico Brasileiro: uma introdução. São Paulo: Konrad Adenauer.

EIFER, Benn; GELB, Alan; TALlROTH, Nils Borje (2003). Managing Oil Wealth. International Monetary Fund: Finance and Development, March 2003, Volume 40, Number 1. Disponivel em http://www.imf.org/external/ pubs/ft/fandd/2003/03/eife.htm

EVANS, Peter (1992). The state as problem and solution: predation, embedded autonomy and structural change, in Stephan Haggart/Robert Kaufman (eds.) Politics of Economic Adjustment. Princeton University Press. Tradução de Cid Knipel Moreira.

FURTADO, Celso (2008). Notas sobre a economia venezuelana e suas perspectivas atuais. In: Ensaios sobre a Venezuela: subdesenvolvimento com abundância de divisas. Rio de Janeiro, Contraponto; Centro Internacional Celso Furtado.

GALL, Norman (2006). Petróleo e Democracia na Venezuela. São Paulo: Instituto Fernand Braudel de Economia Mundial, N. 40.

GALL, Norman (2006). Petróleo e Democracia na Venezuela. São Paulo: Instituto Fernand Braudel de Economia Mundial, N. 41. 
HUMPHREYS, Macartan; SACHS, Jeffrey D.; STIGLITZ, Joseph E (2007). Escaping the Resource Source. New York: Columbia University Press.

KARL, Terry Lynn (1997). The Paradox of Plenty: Oil Booms and Petro-States. Berkeley, Los Angeles and London: University of California Press.

LARSEN, Erling Røed (2004). Escaping the Resource Curse and the Dutch Desease? When and Why Norway Caught up with and Forged ahead of its Neighbors. Oslo: Research Department, Statistics Norway. Discussion Papers No. 377, May 2004.

MORENO, Oscar Landerretche (2009). Governabilidade Macroeconômica e Desenvolvimento Institucional. CARDOSO, Fernando Henrique; FOXLEY, Alejandro (orgs.). América Latina, desafios da democracia e do desenvolvimento: políticas econômicas para além da crise. Rio de Janeiro, Elsevier, vol. 1, pp. 214-250.

NEVES, Rômulo Figueira (2010). Cultura politica e elementos de análise da politica venezuelana. Brasília : Fundação Alexandre de Gusmão.

PAUlA, Ana Paula Paes de (2005). Por uma nova gestão pública: limites e potencialidades da experiência contemporânea. Rio de Janeiro: Editora FGV, p. 21.

PRZEWORKI, Adam (1998). Sobre o desenho do Estado: uma perspectiva agent x principal. In: Pereira, L. C. Bresser e Spink, Peter. Reforma do Estado e administração pública gerencial. Rio de Janeiro: Editora FGV, p. 57.

ROMERO, Carlos A (2010). Venezuela: de um sistema politico a otro. In: I Encontro de Professores e ex-Alunos do Curso para Diplomatas Sul-Americanos. Textos de apoio, volume II - Pensamento. Brasília: FUNAG.

ROSSER, Andrew (2006). The Political Economy of the Resource Curse: A Literature Survey. Brigthon: Institute of Development Studies Working Paper 268, April 2006.

ROSS, Michael L (1999). The Political Economy of the Resource Curse. Cambridge: World Politcs, Vol. 51, N. 2 (Jan, 1999), pp. 297-322. 
ROSS, Michael (2008). But seriously: does oil really hinder democracy? UCLA: Department of Political Science. Preliminary Draft.

ROSS, Michael (2015). A maldição do petróleo. Porto Alegre: CDG.

SACHS, Jeffery D; WARNER, Andrew (1995). Natural Resource Abundance and Economic Growth. Harvard Institute for International Development, Development Discussion Paper no. 517.

SHAFER, D (1994). Winners and Losers: How Sectors Shape the Developmental Prospects of States. Ithaca: Cornell University Press.

YERGIN, Daniel (2010). O Petróleo: uma história mundial de conquistas, poder e dinheiro. São Paulo: Paz e Terra. 